\title{
Application of Indigenous Knowledge Systems in Water Conservation and Management: The Case of Khambashe , Eastern Cape South Africa
}

\author{
Dr P. Mbiji Mahlangu \\ pmahlangu@ufh.ac.za \\ Tendayi C. Garutsa \\ University of Fort Hare, Alice, South Africa \\ tgarutsa@ufh.ac.za
}

Doi:10.5901/ajis.2014.v3n4p151

\begin{abstract}
Indigenous Knowledge Systems are potential transformative tools if they are effectively integrated in water conservation and management systems not only as a matter of redress but also to enrich the current water systems. Local Knowledge systems provide a sound platform for the conservation and management of water in rural areas. The main objective of this study was to identify and investigate the indigenous practises in water management and conservation processes. This study builds upon fieldwork undertaken in the Khambashe rural district in Buffalo City municipality, Eastern Cape. Data collection methods utilised were survey questionnaires, interviews and observation. Statistical data was analysed through the Statistical Package of Social Sciences. The findings indicated that despite a number of values associated with water in the Xhosa culture, loss of ecological and traditional knowledge towards water security confronts many inhabitants. Despite the weak institutional capacities, failure of the state to provide efficient water structures combined with the challenges that Khambashe faces with regards to water, there is failure to recognise and accommodate traditional or cultural values as an alternative to manage and conserve water in rural Khambashe. Relatively a few people still have a strong interest in the indigenous knowledge systems that motivate communities to undertake cultural obligations towards achieving water security.
\end{abstract}

Keywords: Indigenous knowledge systems, Water security, water management and Water security

\section{Introduction}

About 14 million rural and suburban people in South Africa do not have access to running water (Molobela and Sinha, 2011). Despite the importance of water in human development, most people still face a water crisis. About 3.7 million people have no access to any form of water supply infrastructure whilst 5.4 million have to be brought up to a basic level of service (Info, 2006). South Africa is a water scarce country due to its low average annual precipitation (Molobela and Sinha, 2011). The post-apartheid South African government undertook programs to redress the inequalities that were inherited from the apartheid regime. New local and regional institutions, users' registration, licencing and water rights markets were introduced to promote sustainability and efficiency in the water decentralisation systems (Perret, 2002). These systems were aimed at meeting the basic human needs of the rural people. Of paramount importance is that, the traditional water knowledge they possess can enable them to develop their capacities to achieve sustainable and equitable development. The utilization of IKS in the water security processes is based on the fact that indigenous people have successfully managed the ecological and hydrological environments without damaging them (Emery, 1996).

\subsection{Objectives}

The objectives set out for this study were to:

- Identify the indigenous practises and water management and conservation interface in Khambashe rural district.

- To determine the factors limiting the extent to which indigenous knowledge systems are relevant to the water management and security in the Khambashe village.

- To recommend interventions to indigenous methods based on current initiatives so as to improve the 
usefulness and efficiency of water security practices.

Based on the above objectives the next section gives a brief background on the conceptual framework that this study builds upon. It will give a critical review of indigenous knowledge and development, debates surrounding its conceptualisation and how it contributes to development.

\section{Literature Review}

\subsection{Indigenous knowledge and development: A synthesis}

Indigenous knowledge has been viewed as an alternative for achieving rural development and curbing rural poverty. In the post development discourse, indigenous knowledge is a probable alternate for the rural poor. Escobar (1995: 98) mentioned,

“............the remaking of development must start by examining local constructions, to the extent that they are the life and history of people, that is, the conditions for and of change"

In other words, Escobar implies a development discourse that is driven by the rural communities themselves to initiate change. The rural poor should posses a sense of ownership in the development processes. Chambers (1983:2001) concurs with Escobar when he states that the rural poor should have a voice in issues affecting them. Debates surrounding the use of indigenous knowledge in development dates five decades back in Allan's 1965 text on standard narrative on development, population and land pressure. Allan (1965) recognised that indigenous agricultural systems demonstrated knowledge that could positively contribute to development. In addition, a significant number of literature unveils how local knowledge has contributed immensely to rural development (Barker, 1979; Bell, 1979; Belshaw, 1979; Chambers, 1979; Howes, 1979; Richards, 1979; Brokensha et al., 1980; Scoones and Thompson, 1994). A popular view by the above mentioned scholars is the shift from centralised technically oriented solutions towards development projects that valued indigenous knowledge (Agrawal, 1995: 414). Around the 1990s development was discussed in the context of social capital and development which encapsulated indigenous knowledge as part of mainstream development (Eyzagirre, 2001 and World Bank, 1998). Furthermore literature mentioned the acceptance of the indigenous knowledge discourse in development (Warren, 1991, 1992; World Bank, 2000, Shepherd, 2001 and Hubbard, 2001).

However, Briggs (2005) argues that around the late 1990s, they were tensions between indigenous and western claims. Local knowledge rejected western science's claim to universality and its institutionalisation that it can be archived and transferred.

This study concurs with the view that, despite the acknowledgment of the role of indigenous knowledge in development, indigenous knowledge has failed to contribute profusely to the development discourse or mainstream despite the optimism (Sillitoe 2010:12). Briggs 2013 mentions three thematic areas that enlighten why indigenous knowledge has failed to impact on development over the years.

- Indigenous knowledge has been locally and geographically specific i.e. it varies due to geographical, economic and cultural settings. Mapinduzi et al (2003) undertook a study in Tanzania on ecological knowledge by cattle herders on grazing and cropping in local ecologies. Also Mekoya et al (2008) embarked on a study which investigated the differences between the use of local and exotic fodder trees. Watson (2009) also divulged how local knowledge has contributed to promoting biodiversity conservation.

Sillitoe (2010) attributed the failure of Indigenous Knowledge to settings which are different; therefore unless the rural communities share similar economic, geographical and cultural settings, it may be difficult to understand the utility of some indigenous practices or processes. Briggs (2013) mentions how the IK can inform research beyond the context and geographical location undertaken. It might be difficult to use ideas, concepts, results derived from one specific context to the other which poses the problem of universality.

- The second concern raised is how Indigenous Knowledge can be formally integrated with formal science to produce hybrid Knowledge. Barrerra- Basolls et al., (2006) carried a study on the interface between natural and social sciences. Several scholars have embarked on studies related to the integration of Indigenous Knowledge and formal science (Homann et al., 2008; Thomas and Twyman, 2004; Walker et al., 1999; Blanckaert et al., 2007; Lado, 2005; Liwenga, 2008; Marin 2010; Weatherhead et al., 2010).

The challenge of incorporating the two still remains a concern (Hommann et al. 2008, Liwenga; Mercer 2004) although some scholars like Lado, (2005) call for intertwining the two modes of knowledge in a sustainable, realistic 
manner for sustainable development. Despite realistic propositions on how these binaries can integrate, there are issues of power relations between stakeholder groups and knowledge systems themselves (Briggs and Sharp, 2004). Western Knowledge has been prioritised and still there is unwillingness to use IK ignoring local social, cultural and economic priorities.

The third and recent concern raised is the appropriation of indigenous knowledge into the prevailing discourse of neoliberalism (World Bank, 1998; 2007). IK is still seen as a poor relation of Western scientific knowledge. The important grounded nature of IK will be lost in trying to universalise systems which are locally and geographically specific. This runs the risk to serve the needs of capitalism and neoliberalism (Busingye and Keim, 2009, Laurie et al 2005, Nightinggale, 2005).

After discussing the debates surrounding the conceptualisation of Indigenous knowledge and rural development, the following section examines water security definitions and background.

\subsection{Water security background and definitions}

Nearly $80 \%$ (4.8 billion) of the world's population have no access to water and stay where the biodiversity has negatively threatened the availability and use of water. The impact of water scarcity accentuates its threat to dry lands across all continents (Vorosmarty et al., 2010). Grey and Saddoff, (2007) define water security as the availability of an acceptable quantity and quality of water for health, livelihoods, ecosystems and production coupled with an acceptable level of water related risk to people, environments and economies. Furthermore, Campana (2011) defines water security as "the capacity of a population to access sufficient water to meet all needs and to limit the destructive aspects of water. It involves both the productivity and destructivity of water"

The above definitions are inclusive of availability, utilisation as well as sufficiency. Water security can be understood by understanding its extensive implications on food, energy, climate change therefore it may be understood by summarising and incorporating all its potable needs. In this paper water security means ensuring the availability of adequate and reliable water resources of acceptable quality, to underpin water service provision for all economic activity in a manner that is environmentally sustainable. The term water security has been used relatively in literature with an equivalent meaning with food and energy security. However it must be noted that not only its unavailability but its presence that can pose as a peril. Water security is determined by numerous factors which include the hydraulic, socioeconomic and change in the future environment and these will not be dealt with in this paper (Grey and Saddoff 2007)

\subsection{Indigenous knowledge and water security interface}

Mercer et al, (2010) mentions that "indigenous knowledge is considered to be a body of knowledge existing within or acquired by local people over a period of time through accumulation of experiences, society-nature relationships , community practices and institutions by passing it down to other generations." On the other hand, Artur (2011) defines it as "neither genuinely local nor homogeneous and equally shared". IK is socially constructed and can vary from one individual to another.

The interface between indigenous knowledge systems and water security is embodied in the traditional knowledge and skills in managing and protection of water sources (Emery, 1996)). The water knowledge rural societies possess can enable them to develop their capacities to achieve sustainable and equitable development. The utilization of IKS in the water security processes is based on the fact that indigenous people have managed the ecological and hydrological environments without damaging them (Emery, 1996). Ali (2006) mentions that indigenous methods of water resource management and irrigation methods vary from canal, pond and well digging to cultivation of low adaptive crops. It further embodies the soil-moisture relationships, indigenous irrigation, capability of domesticated plants and water resource management methods.

\subsection{Examples of indigenous practices which are relevant to the water sector include:}

$>$ Location, collection and storage of water

$>$ Water resource management and irrigation methods

$>$ Conservation strategies

$>$ Natural forestry management

> Medicinal plants and medicinal practices 
$>$ Hunting fishing and gathering

> Agricultural practices: crop domestication, breeding and management, agro-ecology, crop rotation and pest and soil management.

The following section is the presentation of the findings i.e. the cultural values associated with water management and the indigenous or local strategies used by rural households for sustainable water management in Khambashe.

\section{Empirical Results and Discussions}

The main objective of this study was to identify and investigate the indigenous practises in water management and conservation processes in the Khambashe rural district in Buffalo City municipality, Eastern Cape. Data collection methods utilised were survey questionnaires, interviews and observation. The results will be analysed in the following themes:

- Indigenous knowledge and water management in Khambashe

- Types of rainwater harvesting

- Purpose of rain water harvesting

- Indigenous practices and tools used in Water harvesting and management

- Factors limiting the use of Indigenous methods in water management

\subsection{Profile of sampled informants in Khambashe}

Majority (58\%) 58 of the respondents were women. Forty seventy percent of these were aged between 15-30 years. Most $(68 \%)$ of the respondents were married. About $42 \%$ of them were educated only up to primary school level. Majority (69\%) were subsistence farmers and about $72 \%$ owned between $0.164-2.025$ hectares of land.

\subsection{Indigenous Knowledge and Water Management in Khambashe}

The results indicated that, despite a number of values associated with water in the Xhosa culture, Khambashe inhabitants do not really draw a comprehensive overview of the traditional cultural practice of water in present day. Traditionally in South African history, settlers were drawn to water and natural resources. Settlements were established and abandoned in relation to climatic conditions. Wet years were regarded as periods of prosperity and dry years were marked as times of hardships. Water was an important component in the customary economy with a long tradition of cultural practise and history (Bernard 2006). There is limited ability of indigenous knowledge to inform potential impacts on water security. Loss of ecological and traditional water security confronts many inhabitants. Relatively a few people still have a strong interest in the indigenous knowledge systems that motivate communities to undertake cultural obligations towards achieving water security. This might be attributable to the fact that historically indigenous knowledge has been marginalised from water resource and management processes. Despite the weak institutional capacities, failure of the state to provide efficient water structures combined with the challenges that Khambashe faces with regards to water, there is failure to recognise and accommodate traditional or cultural values as an alternative to manage and conserve water in rural Khambashe. Some informants mentioned that natural resources, including waterways, are pivotal sources of their customary economy. Water ceremonies are no longer prevalent. Elderly men (otata) visited the Xhosa forest which is referred to as ihlathi lesiXhosa or alternatively rivers (umlambo), caves or mountain (intaba) peaks to appease the ancestors for water. These natural landscapes were important sites where ancestors (izinyanya) were situated. One informant mentioned that:

\footnotetext{
"Drought is a sign that the ancestors are displeased with the transgressions of the living, if there is no rain the ancestors are not happy about the way things are handled and the elders should therefore be able to determine why it is so and perform rituals to appease the spirits. On the other hand if things are handled well there will be rains that will provide fertility in the fields and improve agricultural production"
}

Ancestral spirits were linked to a long tradition of practices and history and were considered as mentors and guides to supply people with rains. Similarly Lathan (1986), Aschwanden (1989) and Daneel (1971) mention the presence of a Shona or Karanga Supreme divine being named Dzivaguru or Mwari who provides rain and fertility and mermaids (njuzu) which are closely linked to the python and Puffadder who stays in water shrines central to rainmaking. In the Zulu culture the heavenly princess Inkosazana is believed to bring soft soaking rains which bring great productivity and fertility 
(Benard, 2003). Also the Rain Queen Modjadji of Limpopo was the leader of Balobedu in the Limpopo province and succession of the rain queen title was passed from mother to the eldest daughter as part of the tribal tradition from the $16^{\text {th }}$ Century. Kings like Shaka Zulu travelled to her so she could bless them with rain. The last Queen Makobo Modjadji died in 2005 (The Water Wheel, 2006).

Some informants mentioned that the water rituals were facilitated by diviners (amagqirha) in ceremonies where traditional beer (umqombothi) and other gifts were presented to the ancestors (Izinyanya) to appease them. Whilst older men (otata abadala) spent time in the forests, mountains and water sources for these water ceremonies, the older women's role was to collect firewood (ukutheza) in these forests, occasionally for the rituals. They dressed in traditional outfits referred to as imibhaco. Elderly women were also responsible for preparing the traditional beer (umqombothi) to appease the ancestors. In summary, the elderly are, the holders of local knowledge aimed at managing and conserving water.

Another interesting point mentioned was that water sources provided cultural creation sources and were a link between the ancestors and the people. Waterways are pivotal to the identity of local people in Khambashe and their sense of belonging. Water is an important component in their customary economy. One informant said,

"It is said that the rivers are dwellings of divine beings from the spirit world who provide wisdom, knowledge and protection to humanity like snakes and mermaids"

Benard (2006) similarly mentions that mermaids and snakes reside in rivers, oceans waterfalls which are places of fundamental importance to many of African healing traditions and customs. In Zimbabwean Shona culture the mermaids are known as njuzu and are alien spirits of human and nonhuman origin (Aschwanden, 1989). In addition Zimbabwe was the first African State in Southern Africa in the Limpopo basin surrounded by Sashe and Limpopo rivers (Huffman, 2000). The leader's legitimacy was embodied in the ability to intervene with God and the ancestors to make it rain and the land fertile. The association between chieftaincy and rain was so strong though different from the Bantu Speaking groups where the Ngunis made use of medicines and rituals for their rain making tradition.

Water is source of directly linked to the substance, wellbeing and health of species, food and medicines. One informant mentioned that

\begin{abstract}
"Although indigenous methods and technologies in water management found in rural areas currently are relatively few, there are strong beliefs that traditional healers (amagqirha or alternatively known as izangoma) play a significant role in ensuring that it rains by performing rituals, and there are, also, traditional medicines found in rivers that are directly linked to substance and health"
\end{abstract}

Rains were linked to substance and health controlled by the ancestors marked by the transition from dry to wet season which had a health and mental effect on people. The rain making cultural rites (gofethla pula) around the 1920s was done through traditional music and dancing. This cultural rite had a positive effect on people (during that time of year people were observed to be in good health due to the traditional medicines found in water sources during the rainy seasons). In addition, people were observed talking to themselves and undressing in the public; a clear demonstration of the effect of rain on both the landscape and the mind (Livingston, 2005).

The above section illustrates how water has always been related to cultural connotations and values in most African countries. Despite the loss of traditional ecological knowledge on water indigenous methods have always been used to secure water. The next section will discuss findings on the sources of domestic water in Khambashe.

\title{
3.3 Source of domestic water in Khambashe
}

Khambashe rural community struggles to meet the water demand of its population. Only $10 \%$ of the rural population have access to clean, sustainable water supply (public standpipe) whilst the rest of the community rely on the water tank from the Buffalo municipality which is supposed to deliver water at least once a week but provides the much needed water on an inconsistent basis. Most of the respondents indicated that they do not have access to water from boreholes, piped water in the house, standpipes in the yards, water from rooftop harvesting, nearby streams and public standpipes which are further away from the households. 


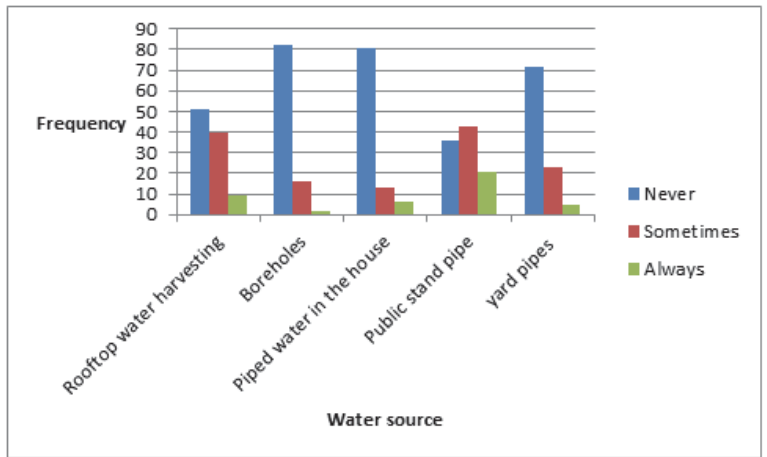

Figure 1: Sources of domestic water used by informants in Khambashe

Results also demonstrate that there were no enforceable water sources or reserves provided by the government except the water tankers, one tap which provided clean and treated water to only but $10 \%$ of the inhabitants of Khambashe. It has become increasingly apparent that there is no access to safe water in this rural area. There is need to develop water systems which ensure that households are linked to better water quality which are sustaining, effective and appropriate to small water systems. Alternative social systems of water like indigenous methods of conserving water are very rare because they are only restricted to the knowledge holders who are the elderly. Similar systems have been experienced in rural Columbia where there is great inequality and discrimination to water supply issues (Carmen, 2005). Some rural areas in Columbia lack access to water compared to urban areas. This further exacerbates the gap in the provision of basic services between the rural poor and the urban populations.

\subsection{Practises used in indigenous water management and conservation}

The relatively common indigenous practise in water management indicated by the results was ploughing. Results also indicated that most of the practises or tools of indigenous water management are not common in present day Khambashe except the practice of digging wells. $90 \%$ of the respondent mentioned that digging wells i.e. eqhuleni in Xhosa was a common practise in Khambashe for water security.

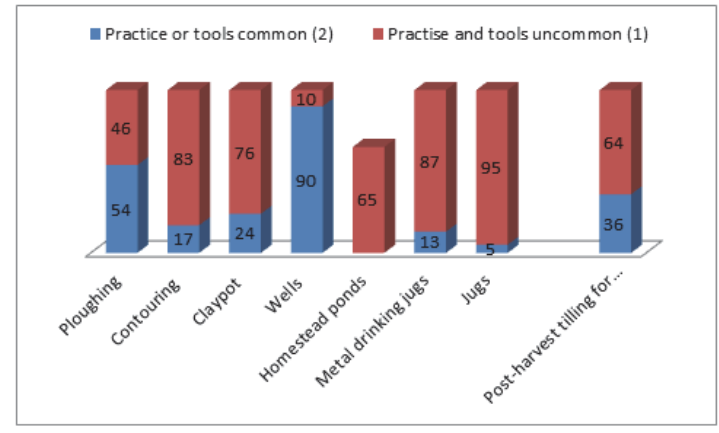

Figure 2: Practices or tools in indigenous water management

None of the respondents was familiar with the matter of creating homestead ponds (Ipitsi in isiXhosa). The practice of conserving water through homestead ponds is largely a $19^{\text {th }}$ century practice that involves collection and storage of rainwater in small dams for crop watering and livestock consumption (Water research commission, 2009). This system was uncomplicated and was aimed at bringing water sources around homesteads to sustain subsistence farming and other household activities. The stored water was collected with hand containers like clay baskets. This system was also popular in the Sotho farmers around the 1970s known as the Matamo system. Furthermore the Water Research 
Commission (2009) mentioned that the indigenous practise of Post-harvest tilling (Gelesha) is used as moisture -holding practice for maximum retention of water.

\subsection{Types of Rain water harvesting}

Rainwater harvesting forms the foundation of many agricultural project since it enhances food production (Mati et al. 2005). Although it reduces crop failures, intra seasonal droughts and floods, results indicate that infield rainwater harvesting is rarely used in Khambashe. Only $20 \%$ of the respondents use post harvesting tiling system for infiltration known as ukugelesha in isiXhosa. 46 respondents mentioned that they were familiar with the use of rooftop rainwater harvesting an indigenised method (indigenous and external influence application) whilst most respondents mentioned that they were not familiar with trench bed gardening (46), infield rainwater harvesting (79) collection of rainwater from slopes (86) and collection of rainwater from the road (68). Results indicate the limited rainwater harvesting methods concurring with WRC's (2009) view that the basis for the few local rainwater harvesting methods manifests from the relatively few indigenous rainwater harvesting methods in South Africa.

\begin{tabular}{|l|c|c|c|}
\hline \multicolumn{1}{|c|}{ Type } & Always & Sometimes & Never \\
\hline Post-Harvest tilling for infiltration (Gelesha) & 8 & 12 & 80 \\
\hline Rooftop rainwater harvesting & 46 & 46 & 8 \\
\hline Collect from runoff from the road & 4 & 28 & 68 \\
\hline Collection from a slope & 4 & 10 & 86 \\
\hline Infield rainwater harvesting & 7 & 14 & 79 \\
\hline Trench bed gardening & 11 & 43 & 46 \\
\hline
\end{tabular}

Table 1: Types of Rainwater Harvesting

Despite the fact that rainwater harvesting is one of the indigenous conservation and water management methods currently used in South Africa (Water Research commission, 2009) it is rarely used in Khambashe. Rainwater harvesting can either be used as either exclusively indigenous, a product of indigenous and external influences or contemporary rainwater harvesting methods. Purpose of rain water harvesting

Results indicated that most people use water for

- Domestic use (81\% of the respondents)

- Pasture Improvements (66\% of the respondents)

- Livestock Production (76\% of the respondents)

- Crop Production (92\% of the respondents)

- Multiple uses (94\% of the respondents)

Conserving and managing water assists to improve water supplies for domestic use, pasture improvement, livestock production, crop production and more multiple uses.

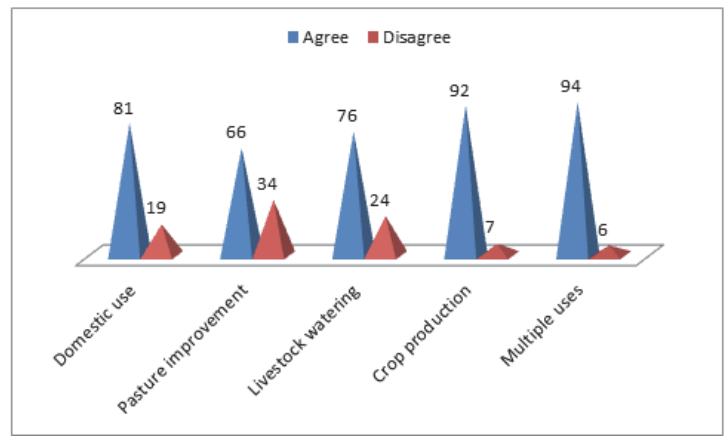

Figure 3: Purpose of conserving and managing water in water in rural areas 
Falkerman and Rockstrom, (2003) mention how important water harvesting is in improving effectiveness of crop production especially in low rainfall regions. They also point out how cultural water management techniques are essential for livestock, crop production and domestic use as they extend the period of water availability. Studies from Southern Africa have shown how farmers have employed indigenous techniques for rainwater retention and conservation methods which retain subsequent rainfall (Waddingtom, 1991; Morse, 1996; Tromlow and Brueeanu, 2000).

\subsection{Factors limiting the use of Indigenous methods in water management}

Results point towards a number of factors which affect the use of indigenous water management and techniques in Khambashe. These include lack of documentation (73), unsupportive patriarchal and cultural structures (74), obsolete and out of date practices (80), unproven scientific procedures (80), time demanding (56) and indigenous knowledge restricted only to the knowledge holders (74).

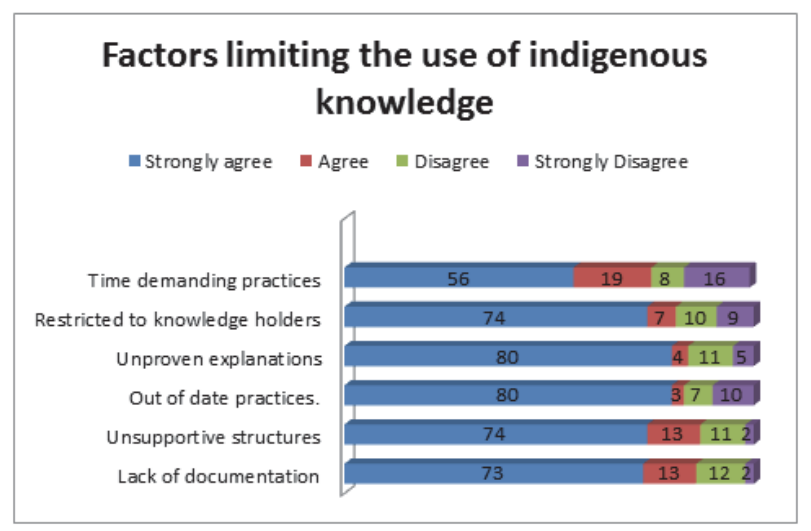

Figure 4: Factors limiting the use of indigenous knowledge

Concurring with this notion is Briggs and Sharp, (2004) who state how indigenous methods have not been utilised in development initiatives. Western Knowledge has been prioritised as it ignores local social, cultural and economic priorities. There is still unwillingness to bring into play either Indigenous Knowledge or hybrid Knowledge.

\subsection{Concluding remarks: Rethinking Indigenous Knowledge Systems in Water Security}

Indigenous water management evolves from accumulated knowledge, practises and traditions from many generations of experimentation and adaption (source). This study examined the distinctly indigenous, indigenised and contemporary methods that rural areas are currently used and how they impact on water management and conservation. The custodians of indigenous knowledge have failed to appropriately disseminate this knowledge to the younger generation resulting to the knowledge being restricted to the elderly. Relatively few people in Khambashe still have a strong interest in the indigenous knowledge systems that motivates communities to undertake cultural obligations towards achieving water security. The use of indigenous methods in the application of water security processes has diminished over the years. Indigenous management and water techniques have potentials of improving water security in rural households. The elderly play a significant role in water security since they are the custodians of local knowledge. Based on the results indicated above, this study recommends:

* The custodians of indigenous knowledge should be capacitated to manage the transmission of local knowledge to the younger generation so that it becomes what Gibbons (2002) terms as socially distributed knowledge.

* There is need to empower local communities through awareness programs so they can actively participate in the development process and enhance good governance from below.

* An integrated approach in water management and conservation where government can foster partnerships between scientists, legal expert and IK practitioners can necessitate supporting scientific validation and form 
knowledge networks.

* Innovative ways can be identified at all resource levels which can be incorporate within existing frameworks on current water systems using locally available materials. This will consequently improve water service provision for social and economic activity in an environmentally stable Knowledge

* Creation of hybrid knowledge and rural people and government need to capacitate so as to be oriented towards improving indigenous technologies and tools and incorporating them into existing modern technologies or applications adapted to secure, manage and conserve water in rural areas.

* Knowledge should be applied to a new holistic approach of economic and relations which are equitable.

* Modern techniques need to encompass the flexibility of indigenous knowledge systems and provide options that can fit into the local biophysical and socio economic circumstances (Tengberg, et al, 1998)

\section{Acknowledgements}

We would like to acknowledge Professor Tally Palmer who provided a research Grant to the Centre for Transdisciplinarity. We also acknowledge the input of the Khambashe participants, research assistants, the NRF particularly Mrs Joyce Forturin for continuously assisting the research team.

\section{References}

Allan, W. 1965: The African husbandman. London:Oliver and Boyd.

Barker, D. 1979: Appropriate methodology: an example using a traditional African board game to measure farmers' attitudes and environmental images. IDS Bulletin 10, 37-40.

Barrera-Bassols, N., Zinck, J.A. and van Ranst, E. 2006: Symbolism, knowledge and management of soil and land resources in indigenous communities: Ethnopedology at global, regional and local scales. Catena 65, 118-37.

Bell, M. 1979: The exploitation of indigenous knowledge or the indigenous exploitation of knowledge: whose use of what for what? IDS Bulletin 10, 44-50.

Belshaw, D. 1979: Taking indigenous knowledge seriously: the case of intercropping techniques in East Africa. IDS Bulletin 10, $24-27$.

Blanckaert, I., Vancraeynest, K., Swennen, R., Espinosa-Garcia, F., Pinero, D. and Lira- Saade, R. 2007: Non-crop resources and the role of indigenous knowledge in semi-arid production of Mexico. Agriculture, Ecosystems and Environment 119, 39-48.

Briggs J. Indigenous knowledge: A false dawn for development and practice. Progress in Development Studies 13, 3 (2013) pp. 231-243

Briggs, J. 2005: The use of indigenous knowledge in development: Problems and challenges. Progress in Development Studies 5, 99114.

Brokensha, D. Warren, D. and Werner, O., editors 1980: Indigenous knowledge systems and development. New York: University Press of America.

Busingye, J. and Keim, W. 2009: The political battlefield: Negotiating space to protect indigenous and traditional knowledge under capitalism.

International Social Science Journal 60, 37-54. Chambers, R. 1979: Editorial. Rural development: whose knowledge counts? IDS Bulletin 10, 1-3.

Escobar, A. 1995: Encountering development: the makingand unmaking of the Third World. Princeton NJ: Princeton University Press.

Eyzaguirre, P.B. 2001: Global recognition of indigenous knowledge: is this the latest phase of 'globalization'? Indigenous Knowledge and Development Monitor 9.

Hart, G. 2001: Development critiques in the 1990s: culs de sac and promising paths. Progress in HumanGeography 25, 649-58.

Homann, S., Rischkowsky, B. and Steinbach, J. 2008: The effect of development interventions on the use of indigenous range management strategies in the Borana Lowlands of Ethiopia. Land Degradation and Development 19, 368-87.

Howes, M. 1979: The uses of indigenous technical knowledge in development. IDS Bulletin 10, 12-23.

Lado, C. 2004: Sustainable environmental resource utilisation: A case study of farmers' ethnobotanical knowledge and rural change in Bungoma district, Kenya. Applied Geography 24, 281-302.

Liwenga, E. 2008: Adaptive livelihood strategies for coping with water scarcity in the drylands of central Tanzania. Physics and Chemistry of the Earth33, 775-79.

Laurie, N., Andolina, R. and Radcliffe, S. 2005: Ethnodevelopment: Social movements, creating experts and professionalising indigenous knowledge. Antipode 37, 470-96.

Mapinduzi, A., Oba, G., Weladji, R. and Colman, J. 2003: Use of indigenous ecological knowledge of the Maasai pastoralists for assessing rangeland biodiversity in Tanzania. African Journal of Ecology 41, 329-36.

Mekoya, A., Oosting, S.J., Fernandez-Rivera, S. and van der Zipp, A.J. 2008: Multipurpose fodder trees in the Ethiopian Highlands: Farmers' preference and relationship of indigenous knowledge of feed value with laboratory indicators. Agricultural Systems 96, 184-94.

Molobela I,P. AND Sinha, P. 2011 Management of Water resources in South Africa: A review. African Journal of Environmental Science and Technology Vol. 5(12), pp. 993-1002, December 2011 
Scoones, I. and Thompson, J., editors 1994: Beyond farmer first: rural people's knowledge, agricultural research and extension practice. London: Intermediate Technology Publications.

Richards, P. 1979: Community environmental knowledge in African rural development. IDS Bulletin 10, 28-35.

Sillitoe, P. 2010: Trust in development: Some implications of knowing in indigenous knowledge. Journal of the Royal Anthropological Institute 16, 12-30.

Nightingale, A. 2005: 'The experts taught us all we know': Professionalization and knowledge in Nepalese community forestry. Antipode 37, 581-604.

World Bank 1998: Indigenous knowledge systems in sub-Saharan Africa: An overview. IK Notes. http://www.worldbank.org/afr/ik

Walker, D., Thorne, P., Sinclair, F., Thapa, B., Wood, C. and Subba, D. 1999: A systems approach to comparing indigenous and scientific knowledge: Consistency and power of indigenous and laboratory assessment of the nutritive value of tree fodder. Agricultural Systems 62, 87-103.

Thomas, D. and Twyman, C. 2004: Good or bad rangeland? Hybrid knowledge, science and local understandings of vegetation dynamics in the Kalahari. Land Degradation and Development 15, 215-31.

Vorosmarty CJ, Green P, Salisbury J, Lammers RB (2010). Global Water Resources: Vulnerability from Climate Change and Population Growth. Sci., 289: 284-288.

Grey, D. and Sadoff C. 'Sink or Swim? Water security for growth and development'. Water Policy 9 (2007): 545-557.

Water Research Commission 2009 